\title{
OVARIOTOMY PERFORMED ON AN INSANE PATIENT, EXEMPLIFYING ALSO THE LIFE HISTORY OF AN UTERINE FIBROID.
}

\author{
By LOMBE ATTHILL, M.D.; \\ Ex-Master of the Rotunda Hospital, Dublin. \\ [Read in the Section of Obstetrics, March 9, 1894.]
}

Although we frequently have patients under observation for years in whom the uterus is the seat of a fibrous tumour, it is seldom that an opportunity is afforded of watching its development from almost its earliest stage till it attains its maximum size, during which we have to combat the various distressing, and, indeed, of ten dangerous symptoms it gives rise to ; then to witness the retrograde metamorphosis which generally commences after the climacteric period is reached; and finally, to verify the fact that the tumour has disappeared, and that the uterus has been restored to almost its normal state. It is mainly because it has fallen to my lot to witness all these phenomena that $I$ bring forward the following case :-

A lady, married some fifteen years, and then aged about thirty-seven, came under my care in 1882. She had never been pregnant, and had enjoyed good health till about two years previously, when, having gone through a period of great mental anxiety, she began to suffer from slight attacks of hæmorrhage, which came on whenever anything occurred to worry or excite her. These sometimes were profuse, probably marking the menstrual periods; but of this she could not be sure, as they recurred irregularly.

On examining her $I$ found the fundus to be enlarged and retro- 
flected, while a small polypus projected from the os uteri. The diagnosis I made at the time was "cervical polypus and probable uterine fibroid." I removed the little polypus, and put her on ergot, but no benefit resulted, and the hæmorrhages became even more profuse. I therefore dilated the cervix, but there was no intra-uterine growth, so I carretted and applied nitric acid freely, and subsequently injected iodised phenol into the cavity. The result of this treatment was that the irregular hamorrhages ceased; but menstruation recurred too soon, and was very profuse and weakening.

For the nine following years I saw this lady frequently. The uterus steadily increased in size, and became nodulated, thus confirming the original diagnosis that its wall was the seat of a fibroid. Finally it attained the size of the foetal head at full term, the fundus reaching nearly to the umbilicus, and friends supposed from her figure that she was pregnant; then she became insane, and was admitted into an asylum, and I lost sight of her.

More than once $I$ had suggested operative interference, for the hæmorrhages were sometimes alarming, but the suggestion would not be listened to. A few weeks ago I was requested to visit this lady in the asylum, the reason being that the abdomen had recently increased rapidly in size, though she herself had become extremely thin. I should say that since she became insane great difficulty had been experienced in getting her to take food.

On visiting her I was told that she had ceased to menstruate soon after her admission into the asylum two years ago. The abdomen was occupied by a large fluctuating cyst, the fibroid which used to be so prominent could not now be felt, and the only question was whether a cyst had been developed in the fibrous tumour whose growth I had so long watched, or was it a recently developed ovarian one. I believed it to be ovarian, but the patient resisted so vigorously that unless under the influence of an anæsthetic anything like a satisfactory examination was impossible.

'The attendants were so clear, judging from her size, that the tumour was increasing rapidly, that I advised that she should be ready for the performance of an abdominal section, if when in an insensible state that seemed advisable, that point to be decided at the time. The patient's mental condition was such that I considered the administration of an anæsthetic twice should, if possible, be avoided.

Her friends agreeing to my suggestions, she was brought 
under the influence of chloroform without trouble, and then the existence of a large ovarian cyst was verified, but no trace of the fibroid could be made out. Ovariotomy was rapidly and easily performed, there were a few adhesions anteriorly, the pedicle was long and easily secured, and the tumour was removed. Then we proceeded to examine the state of the uterus; it was but little larger than it should have been in a woman of her age (forty-nine), and no trace of the nodulated tumour so easily traced three years before could be felt. The rapid atrophy of this tumour was most probably accelerated by, and no doubt in part the result of the insufficient quantity of food she had consumed since she became insane. As already observed, there had been a constant difficulty in getting her to take food, and the one great complaint she made to me was that "they were always forcing her to swallow food." This fact confirms the truth of a rule I have always laid down in the treatment of bleeding fibroids-namely, that it is unwise for such patients to take large quantities of nutritious foods. If you feed highly more blood will be manufactured, the more rapidly will the tumour grow, and the greater will be the loss of blood, specially during the menstrual periods. Moderate, unstimulating diet, and abstinence from spirits, wine, porter, \&c., should in general be the rule in such cases.

This patient.made a rapid recovery, and though very restless, even to the extent of sitting up in the bed frequently during the very day on which the operation had been performed, she had no bad symptom. Her friends hope the operation may result in the improvement of her mental condition; but I fear that these hopes may not be realised. IIer general health certainly is, at the end of only a few weeks, decidedly better, and she takes food comparatively freely now.

Dr. A. J. SMiti remarked that it was a very early age for a uterine fibroid to disappear. Usually the climacteric period was delayed. He knew that Dr. Savage had performed several ovariotomies on lunatics, but without satisfactory results as regards their mental condition. 
Dr. Atrhill, in reply, stated that the operation was done merely to prolong the patient's life. He did not expect any improvement in her mental state, as she was sullen, and improvement, if it is to be looked for, should occur in women who have sexual desire. This patient had not any. The early atrophy of the uterus, he thought, could be explained by her emaciation. When she became insane it was with great difficulty she could be induced to eat. 